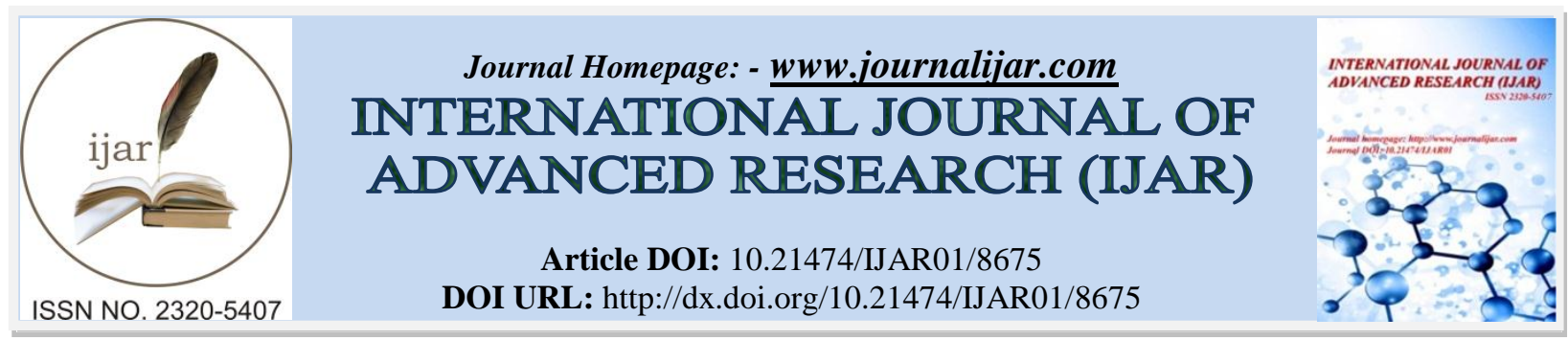

RESEARCH ARTICLE

\title{
CLINICAL AND IMMUNOHISTOCHEMICAL EVALUATION OF THE EFFECT OF PROPOLIS ON ORAL LICHEN PLANUS.
}

Ahmed Abdallah Khalil ${ }^{1}$ and Enas Alaa Eldin Abd El-Aziz ${ }^{2}$.

1. Lecturer of Oral Medicine, Oral Diagnosis and Periodontology, Faculty of Dentistry, Minia University, Egypt.

2. Lecturer of Oral and Maxillofacial Pathology, Faculty of Dentistry, Minia University, Egypt.

\section{Manuscript Info}

Manuscript History

Received: 12 January 2019

Final Accepted: 14 February 2019

Published: March 2019

Key words:-

Propolis, Oral Lichen Planus,

Transforming growth factor- $\beta 1$.

\section{Abstract}

Aim: To evaluate the possible effects of Propolis on atrophic-erosive form of oral lichen planus.

Study design: The study was conducted on 20 patients with atrophicerosive oral lichen planus. The patients were selected from the out patients clinic of the Oral Medicine, Oral Diagnosis, and Periodontology Department, Faculty of Dentistry, Minia University, Egypt.

Methodology: the 20 patients were classified into two groups; Group A: treated by $0.1 \%$ topical triamcinolone acetonide paste and Group B: treated by 5\% Propolis. Each patient was monitored every 2 weeks for 8 weeks. The objective and subjective clinical progress were assessed using the Clinical Score and Visual Analog Scale. Biopsies were taken at baseline and after 8 weeks of treatment and stained immunohistochemically for tranforming growth factor- $\beta 1$.

Results: There was significant improvement in all clinical outcomes within the follow up periods when compared with the baseline ( $\mathrm{P}$ $<0.05)$. A non-significant difference was found between both studied groups at the end of week 8 in terms of VAS and CS scores $(\mathrm{P}>0.05)$. Immunhistochemical evaluation revealed a significant reduction in transforming growth factor $\beta 1$ expression in both groups $(\mathrm{P}<0.05)$ while a non-significant difference was found between the studied groups $(\mathrm{P}>0.05)$.

Conclusions: Propolis can be used as an alternative therapy for treatment of oral lichen planus.

Copy Right, IJAR, 2019,. All rights reserved.

\section{Introduction:-}

Oral Lichen planus (OLP) is a chronic inflammatory disease mediated by $\mathrm{T}$ lymphocytes. It tends to occur more frequently than cutaneous form and affects women more than men (Carrozzo and Gandolfo, 1999; Al-Hashimi et al, 2007; Baccaglini et al, 2013). OLP patients seek therapy because of burning sensation from atrophic or ulcerative epithelium, caused by epithelial apoptosis (Sugerman et al, 2002; Hussein, 2007).

The definitive diagnosis of OLP is confirmed by the histopathologic features of degeneration of basal cells and infiltration of inflammatory cells into the subepithelial layer of connective tissue (Boyd and Nelder, 1991). 
OLP pathogenesis is multifactorial, several cytokines (Chen et al, 2007; Rhodus et al, 2007; Lavanya et al, 2011), adhesion molecules (Norris, 1990) and apoptosis-related molecules (Sklavounou-Andrikopoulou et al, 2004; Hamdy et al, 2016) are involved in its pathogenesis and these factors have been found to be overexpressed in tissues and in oral fluids of patients with OLP (Chen et al, 2007; Sklavounou-Andrikopoulou et al, 2004; Hamdy et al, 2016; Carmeliet, 2003; Metwaly et al, 2014).

Tranforming growth factor- $\beta 1$ (TGF- $\beta 1)$ is a cytokine secreted by most immune cells and it regulates many cellular processes including cell proliferation, differentiation, apoptosis, angiogenesis and tumorigenesis (Elliott and Blobe, 2005).

TGF- $\beta 1$ regulates the expression and activity of matrix metalloprotienase MMPs by regulating the synthesis of tissue inhibitors of the matrix metalloproteinases TIMPs (Elliott and Blobe, 2005; Overall et al, 1991). MMP are capable of digesting extracellular matrix and basement membrane components and damage the epithelial basement membrane indirectly (Sugerman et al, 2002).

Corticosteroids have been for several years the first line of treatment for OLP (Burket et al, 2008). However, because of their adverse effects, alternative therapeutic approaches are being carried out.

Recently propolis has gained considerable interest. It is a sticky, resinous substance that honey bees collect from various plants, and mix with wax and other secretions (Wagh, 2013). It has been used in folk medicine for thousands of years and is also known as Russian penicillin (Kuropatnicki et al, 2013).

Propolis, because of its high bioflavonoid content, has antioxidant, antibacterial, antifungal, antiviral, immunomodulatory, and anti-inflammatory properties. These properties have prompted investigators to check its efficacy on various oral diseases, namely oral candidiasis, recurrent aphthous stomatitis, radiation mucositis, denture stomatitis, and herpes labialis (Arshiya et al, 2013).

This study was conducted to assess the effects of propolis on atrophic-erosive OLP and evaluate the effects clinically and immunohistochemically compared with using corticosteroids.

\section{Subjects and Methods:}

\subsection{Subjects}

The current study was conducted on twenty patients (male and female) suffered from atrophic-erosive OLP and selected from the outpatient clinic of Oral Medicine, Oral Diagnosis and Periodontology Department, Faculty of Dentistry, Minia University, Egypt. Informed consents were obtained from all patients before starting the study practice.

All patients have been clinically diagnosed as OLP (based on modified WHO clinical criteria, 2003) (van der Meij and van der Waal, 2003). The diagnosis was confirmed by taking oral mucosal incisional biopsy specimens of approximately $5 \mathrm{~mm}$ from a marker lesion before starting the treatment (baseline). The histopathological diagnosis of OLP was done by two experienced oral pathologists in department of Oral and Maxillofacial Pathology, Faculty of Dentistry, Minia University, Egypt.

\subsubsection{Study inclusion/exclusion criteria} Inclusion criteria:

- $\quad$ Patients age range (30-60 years) with symptomatic oral lesion clinically and histologically proven to be OLP.

- Patients who had not used systemic or topical glucocorticosteroids for at least past 3 months.

- Patients who agree not to use any other medication such as analgesics and anesthetics in either topical or systemic form during the study.

\section{Exclusion criteria:}

- Patients with any malignant lesion or viral infection.

- Smokers, pregnant and lactating female patients.

- Patients allergic to bee products. 
All subjects $(\mathrm{N}=20)$ were randomly classified into two equal groups:

Group A (10 patients): were treated by $0.1 \%$ topical triamcinolone acetonide paste (Adcortyl, Bristol-Myers Squibb, Anagni, Italy).

Group B (10 patients): were treated by $5 \%$ propolis.

\subsection{Pretreatment Evaluation}

At the first evaluation, the patients' age, gender, date of initial diagnosis of their OLP, medical and dental histories were carefully taken. Clinical oral inspection was performed, extension of the lesions was recorded photographically and baseline data were collected.

\subsection{Treatment Protocol}

The selected patients of 'Group A' were instructed to apply a thin layer of triamcinolone acetonide $0.1 \%$ paste on the oral lesions, 4 times daily, for a total of 2 months. Patients of 'Group B' were instructed to use a thin layer of 5 $\%$ propolis repeated 4 times daily.

All patients were instructed to apply the study medications on dried lesions after meals without eating, drinking, smoking or speaking for at least 30 minutes afterward and the last time before sleeping.

All patients were evaluated regularly at two weeks interval after treatment for eight weeks.

\section{$2.4 \quad$ Assessment of Clinical Outcomes}

At each visit, both objective measurements and subjective severity scores were obtained. All patients were examined generally for any abnormal alteration in the appearance of mucosa (atrophy, telangiectasia, or infection). The response rate was assessed clinically by two outcome measures.

\subsubsection{Assessment of clinical response (sign)}

A marker lesion, identified by being the most severe and extensive lesion, was digitally photographed. All photos were assessed for areas of reticulation, erosion, and ulceration before and after application of the topical therapy. Visual examination was performed using clinical scoring (CS) (Huskisson et al, 1976) (Table 1).

\subsubsection{Assessment of pain and discomfort (symptoms)}

The symptomatic score was obtained using a Visual Analog Scale (VAS) (Huskisson et al, 1976). Patients were asked to score their intensity of pain at each visit as follow: $0=$ no pain, $1=$ mild pain, $2=$ moderate pain and $3=$ severe pain. Patients were requested to mark the scale at follow-up visits. In this way, it was possible to obtain the patient's own evaluation without any interference and/or interpretation by the clinical investigators. All patients were assessed at baseline (before the treatment) and regularly after treatment every other week at the 2 nd (visit 1), 4th (visit 2), 6th (visit 3) and 8th (visit 4) weeks. The score of each visit was statistically compared to the baseline. The differences between baseline and scores of each visit numerically express the clinical and symptomatic improvement.

\subsection{Histopathological evaluation of treatment outcome}

2.5.1. Surgical Material

Surgical biopsy specimens were collected from all patients at baseline and after treatment (after 8 weeks). Clinically normal non- affected tissues away from OLP lesions were taken by punch biopsy from the 20 cases of OLP patients (mainly from operculum covering upper or lower wisdom) and served as control group. These specimens were identified by $\mathrm{H} \& \mathrm{E}$ stain as normal tissues.

The tissue specimens were fixed in $10 \%$ buffered formalin, routinely processed and embedded in paraffin. Serial sections were cut at $5 \mu \mathrm{m}$ thickness, and stained with hematoxylin and eosin $(\mathrm{H} \& \mathrm{E})$. Another set of sections were used for immunohistochemical staining for TGF- $\beta 1$. 


\subsubsection{Immunohistochemistry}

\subsubsection{Antibodies}

A mouse polyclonal antibody to TGF- $\beta$ type 1 (SANTA CRUZ (Santa Cruz, CA) ) was used in the study.

\subsubsection{Technique}

Immunohistochemical staining was performed using a peroxidase labeled streptavidin biotin complex. Five $\mu \mathrm{m}$ thick sections of paraffin embedded tissues were deparaffinized in xylene and routinely processed through ascending hydrated alcohol. Endogenous peroxidase activity was blocked with $0.3 \%$ hydrogen peroxide in methanol.

For antigen retrieval, the sections were heated in a microwave with $10 \mathrm{mM}$ citrate buffer $(\mathrm{pH}$ 6.0) for 10-20 min followed by cooling at room temperature (RT) for $20 \mathrm{~min}$ and then incubated with $10 \%$ normal goat serum for 30 minutes to block non-specific binding. A mouse polyclonal antibody for TGF- $\beta$ type 1 (dilution 1:50) diluted in phosphate-buffered saline (PBS) was applied directly to the slides and incubated at $4^{\circ} \mathrm{C}$ overnight.

The sections were treated with secondary antibodies and then detected using streptavidin biotin conjugates (Vectastain ABC kit, Vector Laboratories, Burlingame, CA). The sections were incubated for 30 minutes at RT for both steps. Visualization of the reaction products was developed with $0.02 \% 3$, 3-' diaminobenzidine in $0.05 \mathrm{M}$ Tris$\mathrm{HCl}(\mathrm{pH}$ 7.4)containing $0.005 \%$ hydrogen peroxide (DAB substrate kit, Vector Lab). The sections were counterstained with hematoxylin. Positive controls were used from sections associated with the kit. Negative control sections were treated identically except that the primary antibody was replaced with nonimmune serum in the PBS.

\subsubsection{Analysis of TGF- $\beta 1$ staining:}

For the analysis of immunostaining, the slides were examined with a light microscope (Leica, Germany). Tissue sections were scanned at X100 magnification for detection of the highest immunopositive areas, and then five microscopic fields were selected at a magnification of X200.

Photomicrographs were captured using a digital camera mounted on the light microscope. TGF- $\beta 1$ immunohistochemistry was evaluated using a semiquantitative immunoreactive score based on their staining intensity ( $0-3$ points) as follows: 0 : no staining at all; 1 : weak staining; 2 : moderate staining; and 3 : strong staining.

\subsection{Statistical Analysis}

The results were statistically analyzed using statistical package for social science (SPSS for Windows, release 15.0; SPSS, Inc., Chicago, IL). Fisher's exact test and Student's t-test were used to obtain statistically significant differences between two groups with $P<0.05$ being considered statistically significant. For statistical analysis of the immunoscores, Chi-square test for proportion was performed.

Table (1): Clinical scoring of oral lichn planus lesions

\begin{tabular}{|c|c|}
\hline Score & Clinical lesion \\
\hline $\mathbf{0}$ & Represented no lesion/normal mucosa. \\
\hline $\mathbf{1}$ & Mild white striae/ no erythematous area. \\
\hline $\mathbf{3}$ & White striae with atrophic area less than $1 \mathrm{~cm}^{2}$ \\
\hline $\mathbf{4}$ & White striae with atrophic area more than $1 \mathrm{~cm}^{2}$. \\
\hline $\mathbf{5}$ & White striae with erosive area less than $1 \mathrm{~cm}^{2}$. \\
\hline
\end{tabular}

\section{Results:-}

\section{$3.1 \quad$ Clinical Data}

20 patients divided into two groups (each including 10 patients) were investigated. Group A included 4 men (40\%) and 6 women (60\%) with an average age of 48.8 years. Group B included 3 men (30\%) and 7 women (70\%) with an average age of 51.5 years. Buccal mucosa was affected in all patients, lips in 2 cases, tongue in 7 cases and gingiva in 2 cases. The form of the lesions was atrophic-erosive form, reticular form was excluded.

\subsection{Clinical outcome of treatment:}

Patients showed improvement in all clinical outcomes within the follow up periods of both studied group. CS and VAS scores decreased in both study groups. The improvement started to appear after 2 weeks of drug application. 
After eight weeks of treatment with propolis, there was great reduction in erythema and erosion but without complete disappearance. However, patients treated with corticosteroid showed total regression and disappearance of erythema and erosion (Fig 1).

During therapy, bad taste, nausea, dry mouth and sore throat occurred in $20 \%$ of group (A) patients in the first week of drug application as minor side-effects from topical steroids.

\subsection{Immunohistochemical results:}

3.2.1. TGF- $\beta 1$ expression in normal tissue:

TGF- $\beta 1$ was rarely detected in the normal oral mucosa specimens. Of the 20 normal oral mucosa specimens, three specimens (15\%) stained weakly for TGF- $\beta 1$ in the cytoplasm of the basal cells (Table 2 ).

\subsubsection{TGF- $\beta 1$ expression in Oral lichen planus:}

Before TTT, TGF- $\beta 1$ was mainly expressed in the cytoplasm of the basal, spinous and granular cell layers of the epithelium and of the subepithelial lymphocytic infiltrate cells. TGF- $\beta 1$ was detected in 17 specimens $(85 \%)$ and the immunostaining varied from moderate to strong. After TTT, only 5 specimens of group A showed mild to moderate expression of TGF- $\beta 1(50 \%)$ while 6 out of 10 of group B specimens showed mild to moderate expression of TGF$\beta 1(70 \%)$ (Table 3, Fig 3).

\subsection{Statistical results:}

There is significant improvement in all clinical outcomes within the follow up periods of both studied group (P < 0.05 for all) (Table 3, 4). There were no significant differences between "change from baseline median values" of studied groups at the end of week 8 in terms of VAS and CS scores $(\mathrm{P}>0.05)$.

Immunohistochemically, there was significant difference in TGF- $\beta 1$ expression between normal oral mucosa and specimens of OLP $(\mathrm{P}<0.0001)$. In both studied groups, a significant decrease in TGF- $\beta 1$ expression was found before and after treatment (Table 5,6) while a non-significant difference was found between both groups (Table 7).

A

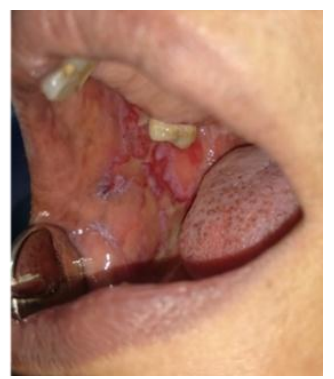

B

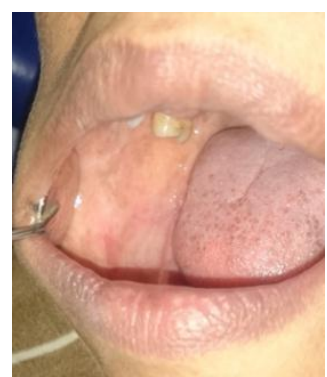

C

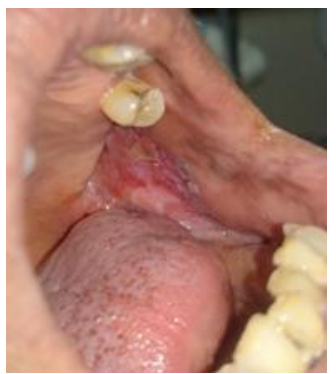

D

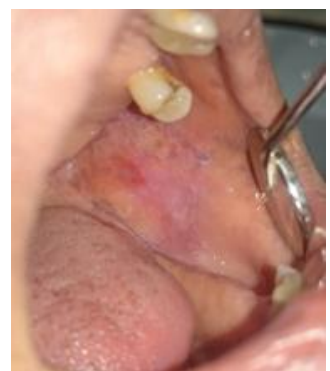

Fig. (1):- Clinical outcome (A) Patient of group A at baseline. (B) Patient of group (A) 8 weeks posttreatment. (C) Patient of group B at baseline. (D) Patient of group (B) 8 weeks posttreatment.

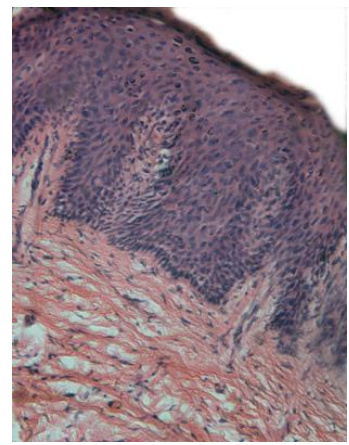

Fig. (2):- oral lichen planus: hyperparakeratosis, saw-tooth profile of rete ridges, liquefaction degeneration of basal cell layer, and compact band-like lymphoplasmacytic infiltrate of multiple cell types below the epithelium (hematoxylin-eosin stain, 200X). 
A

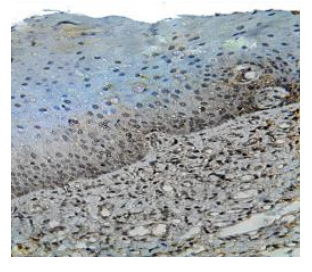

B

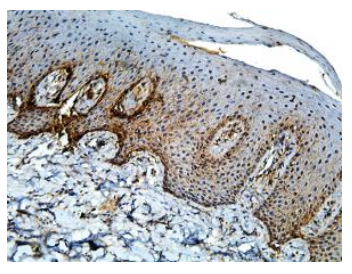

C

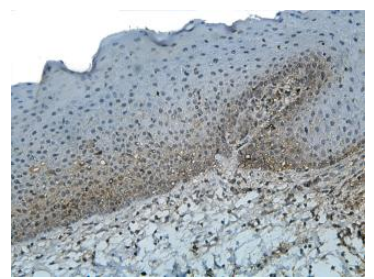

D

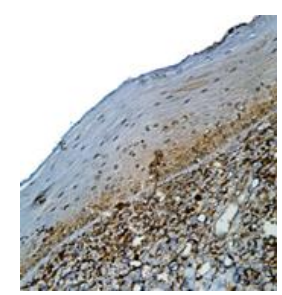

Fig. (3):- TGF- $\beta 1$ expression. (A) Normal oral mucosa. (B) Non-trearted oral lichen planus. (C) Corticosteroid treated oral lichen planus. (D) Propolis treated oral lichen planus (200X).

Table (2): Percent staining of TGF- $\beta 1$ in different groups

\begin{tabular}{|c|c|}
\hline Group & No of patients percentage \\
\hline Normal oral mucosa $(\mathrm{n}=20)$ & $3(15 \%)$ \\
\hline Baseline $(\mathrm{n}=20)$ & $17(85 \%)$ \\
\hline Group $(\mathrm{A})(\mathrm{n}=10)$ & $5(50 \%)$ \\
\hline Group(B) $(\mathrm{n}=10)$ & $6(60 \%)$ \\
\hline
\end{tabular}

Table (3):- Showing Mean and Standard Deviation of VAS in the studied groups. The results showed improvement of the painful symptoms in both groups

\begin{tabular}{|c|c|c|c|c|c|}
\hline \multirow{2}{*}{ Studied groups } & \multicolumn{5}{|c|}{ Mean + SD } \\
\cline { 2 - 6 } & Baseline & 2 weeks & 4 weeks & 6 weeks & 8 weeks \\
\hline Group A & $2.13 \pm 0.72$ & $1.23 \pm 0.28$ & $0.45 \pm 0.06$ & $0.12 \pm 0.06$ & $0.0 \pm 0.0$ \\
\hline P- Value & --- & $\mathrm{P}<0.000^{* * *}$ & $\mathrm{P}<0.000^{* * *}$ & $\mathrm{P}<0.000^{* * *}$ & $\mathrm{P}<0.000^{* * * *}$ \\
\hline Group B & $2.27 \pm 0.61$ & $1.45 \pm 0.42$ & $0.75 \pm 0.12$ & $0.28 \pm 0.11$ & $0.1 \pm 0.04$ \\
\hline P- Value & --- & $\mathrm{P}<0.000^{* * *}$ & $\mathrm{P}<0.000^{* * *}$ & $\mathrm{P}<0.000^{* * *}$ & $\mathrm{P}<0.000^{* * * *}$ \\
\hline
\end{tabular}

$* \mathrm{P}<0.05$ significant $* * \mathrm{P}<0.001$ moderate significance $* * * \mathrm{p}<0.000$ highly significance

Table (4):- Showing Mean and Standard Deviation of CS in studied groups. The results showed decrease of the lesion size in both groups

\begin{tabular}{|c|c|c|c|c|c|}
\hline \multirow{2}{*}{ Studied groups } & \multicolumn{5}{|c|}{ Mean + SD } \\
\cline { 2 - 6 } & Baseline & 2 weeks & 4 weeks & 6 weeks & 8 weeks \\
\hline Group A & $3.96 \pm 1.08$ & $2.12 \pm 0.56$ & $2.03 \pm 0.47$ & $1.02 \pm 0.33$ & $0.45 \pm 0.08$ \\
\hline P- Value & --- & $\mathrm{P}<0.001^{* *}$ & $\mathrm{P}<0.000^{* * *}$ & $\mathrm{P}<0.000^{* * * *}$ & $\mathrm{P}<0.000^{* * * *}$ \\
\hline Group B & $3.92 \pm 1.04$ & $2.56 \pm .83$ & $2.23 \pm 0.56$ & $1.18 \pm 0.45$ & $0.61 \pm 0.11$ \\
\hline P-Value & --- & $\mathrm{P}<0.04^{*}$ & $\mathrm{P}<0.000^{* * *}$ & $\mathrm{P}<0.000^{*} * *$ & $\mathrm{P}<0.000^{* * *}$ \\
\hline
\end{tabular}

*Significant $\mathrm{p}<0.05$

Table (5):- Comparison of distribution of individuals according to the staining intensity of TGF $\beta-1$ scores before and after treatment with corticosteroids

\begin{tabular}{|c|c|c|c|c|c|c|}
\hline \multirow{2}{*}{ Groups } & \multicolumn{4}{|c|}{ score } & \multirow{2}{*}{ Total } & \multirow{2}{*}{ P-value } \\
\cline { 2 - 5 } & 0.00 & 1.00 & 2.00 & 3.00 & & \multirow{2}{*}{0.05} \\
\hline Pre treatment & 3 & 0 & 3 & 4 & 10 & \\
& $(30.0 \%)$ & $(0.0 \%)$ & $(30.0 \%)$ & $(40.0 \%)$ & $(100.0 \%)$ & \\
\hline Corticosteroids & 5 & 3 & 2 & 0 & 10 \\
& $(50.0 \%)$ & $(30.0 \%)$ & $(20.0 \%)$ & $(0.0 \%)$ & $(100.0 \%)$ & \\
\hline Total & 8 & 3 & 5 & 4 & 20 \\
& $(40.0 \%)$ & $(15.0 \%)$ & $(25.0 \%)$ & $(20.0 \%)$ & $(100.0 \%)$ & \\
\hline
\end{tabular}

Significant $\mathrm{p}<0.05$ 
Table (6):- Comparison of distribution of individuals according to the staining intensity of TGF $\beta-1$ scores before and after treatment with propolis

\begin{tabular}{|c|c|c|c|c|c|c|}
\hline \multirow[t]{2}{*}{ Groups } & \multicolumn{4}{|c|}{ score } & \multirow[t]{2}{*}{ Total } & \multirow[t]{2}{*}{ P-value } \\
\hline & 0.00 & 1.00 & 2.00 & 3.00 & & \\
\hline Pre treatment & $\begin{array}{c}0 \\
(0.0 \%)\end{array}$ & $\begin{array}{c}0 \\
(0.00 \%)\end{array}$ & $\begin{array}{c}5 \\
(50.0 \%)\end{array}$ & $\begin{array}{c}5 \\
(50.0 \%) \\
\end{array}$ & $\begin{array}{c}10 \\
(100.0 \%)\end{array}$ & \multirow[t]{3}{*}{0.05} \\
\hline propolis & $\begin{array}{c}4 \\
(40.0 \%) \\
\end{array}$ & $\begin{array}{c}3 \\
(30.0 \%)\end{array}$ & $\begin{array}{c}3 \\
(30.0 \%) \\
\end{array}$ & $\begin{array}{c}0 \\
(0.00 \%)\end{array}$ & $\begin{array}{c}10 \\
(100.0 \%)\end{array}$ & \\
\hline Total & $\begin{array}{c}4 \\
(20.0 \%) \\
\end{array}$ & $\begin{array}{c}3 \\
(15.00 \%) \\
\end{array}$ & $\begin{array}{c}8 \\
(40.0 \%) \\
\end{array}$ & $\begin{array}{c}5 \\
(25.0 \%) \\
\end{array}$ & $\begin{array}{c}20 \\
(100.0 \%) \\
\end{array}$ & \\
\hline
\end{tabular}

Significant $\mathrm{p}<0.05$

Table (7): Comparison of distribution of individuals according to the staining intensity of TGF $\beta-1$ scores after treatment with corticosteroids and after treatment with propolis

\begin{tabular}{|c|c|c|c|c|c|c|}
\hline \multirow{2}{*}{ Groups } & \multicolumn{4}{|c|}{ score } & \multirow{2}{*}{ Total } & \multirow{2}{*}{ P-value } \\
\cline { 2 - 5 } & 0.00 & 1.00 & 2.00 & 3.00 & & \\
\hline Corticosteroids & 5 & 3 & 2 & 0 & 10 & 0.07 \\
& $(50.0 \%)$ & $(30.0 \%)$ & $(20.0 \%)$ & $(0.0 \%)$ & $(100.0 \%)$ & \\
\hline Propolis & 4 & 3 & 3 & 0 & 10 \\
& $(40.0 \%)$ & $(30.0 \%)$ & $(30.0 \%)$ & $(0.0 \%)$ & $(100.0 \%)$ & \\
\hline Total & 9 & 6 & 5 & 0 & 20 \\
& $(45.0 \%)$ & $(30.0 \%)$ & $(25.0 \%)$ & $(0.00 \%)$ & $(100.0 \%)$ & \\
\hline
\end{tabular}

Significant $\mathrm{p}<0.05$

\section{Discussion:-}

Corticosteroids have been the mainstay for treatment of oral lichen planus for several years because of their ability to modulate inflammation and immune response (Eisen et al, 2005). However, some patients are resistant to the topical therapy with corticosteroids (Hamidreza et al, 2015). Lack of adherence of topical corticosteroids to the mucosa is another disadvantage in their using (Eisen et al, 2005). Moreover, in severe and extensive cases systemic corticosteroids are used in higher dose, which may lead to unfavorable side effects especially if used for a prolonged period. These serious side effects of corticosteroids encouraged the researchers to search for a new medication that has similar clinical efficacy to corticosteroid but safer and shows minimal side effects (Hamdy et al, 2017).

Propolis has potent anti-inflammatory, immunomodulatory and antiulcerative effects because of its falvonoids content (Diaz et al, 1997). These compounds play a significant role in inhibition of prostaglandins and leukotrienes synthesis by macrophages. Moreover, they have inhibitory effects on myeloperoxidase activity, NADPH-oxidase, ornithine decarboxylase and tyrosine-protein-kinase (Miyataka et al, 1997). They inhibit the activation and differentiation of mononuclear macrophages (Hu et al, 2005).

The present work assessed the possible effects of topical application of propolis on OLP in comparison with topical corticosteroids both clinically and histopathologically.

In the present study, a significant improvement of clinical outcomes in patients with OLP treated with topical application of propolis and corticosteroids was found. Both propolis and triamcinolone acitonide therapy resulted in reduction of painful symptoms, decrease in lesion size and improved patient's quality of life during two month period. The improvement started to appear after two weeks of topical drugs application. However, the results were more obvious with corticosteroid treatment.

No significant differences were found between the therapeutic effects of triamcinolone acitonide and topical propolis ( $p>0.05)$ as regards the clinical outcomes of OLP after treatment. These findings indicated that topical propolis has a similar therapeutic efficacy of triamcinolone acitonide for treatment of OLP.

These results were in agreement with those of Wael et al, 2015 who reported that topical propolis application accelerated the healing process of diabetic wounds in experimental animal models. 
The average immunoscores of TGF- $\beta 1$ of OLP specimens were higher than that of normal oral mucosa specimens indicating that TGF- $\beta 1$ plays a role in OLP pathogenesis. This result is fully compatible with the notion that MMP expression is increased in OLP compared with normal oral mucosa since the activation of the MMPs can activate TGF- $\beta 1$ (Yu et al, 2008).

After treatment, there was a decline in TGF- $\beta 1$ expression in both groups but the decrease was more prominent in corticosteroid treated group. Our observation of decreased expression TGF- $\beta 1$ in patients treated with propolis is line with that of Moura et al, 2011 who revealed a regulatory effect of water extract of propolis on TGF- $\beta 1$ in sponge implants of mice.

The effect of propolis on TGF- $\beta 1$ could be explained by the ability of propolis to produc a significant decline in the relative number of regulatory T cells expressing IL-10 or TGF- $\beta 1$ (Zauhani et al, 2017).

The immunohistochemical results of reduced TGF- $\beta 1$ expression explain the improvement of propolis treated group clinically since deficient antigen-specific immunosuppression mediated by TGF- $\beta 1$ plays a role in OLP chronicity (Sugerman et al, 2002).

\section{Conclusion:-}

In conclusion, $5 \%$ propolis can be used in treatment of OLP as an alternative to topical corticosteroid.

\section{References:-}

1. Al-Hashimi I, Schifter M, Lockhart P, Brennan M, Bruce A, Epstein J, Lozada-Nur F, Silverman B, Thornhill M, van der Waal I (2007): Oral Lichen Planus and Oral Lichenoid Lesions: Diagnostic And Therapeutic Considerations. Oral Surg Oral Med Oral Pathol Oral Radiol Endod; 103, S25: 1-12.

2. Arshiya Ara S, Ashraf S, Arora V, Rampure P (2013): Use of Apitherapy as a Novel Practice in the Management of Oral Diseases: A Review of Literature. J Contemp Dent.; 3: 25-31.

3. Baccaglini L, Thongprasom K, Carrozzo M, Bigby M (2013): Urban Legends Series: Lichen Planus. Oral Dis; 19: 128-43.

4. Boyd A and Nelder K (1991): Lichen Planus. J Am Acad Dermatol; 25: 593-619.

5. Burket L, Greenberg M, Glick M, Ship J. Hamilton, Ont: BC Decker (2008): Burket's Oral Medicine.

6. Carmeliet P (2003): Angiogenesis in Health and Disease. Nat Med. ;9:653-60.

7. Carrozzo M, Gandolfo S (1999): The Management of Oral Lichen Planus. Oral Dis; 5:196-205.

8. Chen X, Liu Z, Yue Q (2007): The Expression of TNF-Alpha and ICAM-1 in Lesions of Lichen Planus and Its Implication. J Huazhong Univ Sci Technol Med Sci.; 27:739-41.

9. Diaz N, Quevedo A, Luna S (1997): Determination of Fe, Mn, Zn, and Cu in an Ethanolic Extract of Cuban Propolis. Rev. CENIC. Ciências Químicas, 28, 93-5.

10. Eisen D, Carrozzo M, Bagan Sebastian JV, Thongprasom K (2005): Oral Lichen Planus: Clinical Features and Management. Oral Dis.; 11: 338-49.

11. Elliott RL, Blobe GC (2005): Role of Transforming Growth Factor Beta in Human Cancer. J Clin Oncol; 23: 2078-2093.

12. Hamdy A, Fatma F, Mohamed A (2016): Role of Caspase-3 and Tumor Necrotizing Factor-Alpha (TNF-A) Proteins Expression in Oral Lichen Planus: Clinical-Pathological Relation. E.D.J. ;62:4359-68.

13. Hamdy M, Mohamed E, Fatma F (2017): Evaluation of the Efficacy of Topical Timolol Therapy on Oral Lichen Planus: Clinical and Immunohistochemical Study. Journal of Advances in Medicine and Medical Research, 24(8): 1-13.

14. Hamidreza M, Kianoush F, Fatemeh R (2015): A Study of the Effects of CO2 Laser Therapy on Oral Lichen Planus (OLP). J. Appl. Environ. Biol. Sci., 5(9S) 114-118.

15. Hu F, Hepburn H, Li Y, Chen M, Radloff S, Daya S (2005): Effects of Ethanol and Water Extracts of Propolis (Bee Glue) on Acute Inflammatory Animal Models. J. Ethnopharmacol., 100, 276-83.

16. Huskisson EC, Jones J, Scott PJ (1976): Application of Visual-Analogue Scales to the Measurement of Functional Capacity. Rheumatol Rehabil. ;15:185-7.

17. Hussein M (2007): Evaluation of Angiogenesis in Normal and Lichen Planus Skin By CD34 Protein Immunohistochemistry: Preliminary Findings. Cell Biol Int. ;31:1292-5.

18. Kuropatnicki AK, Szliszka E, Krol W (2013): Historical Aspects of Propolis Research in Modern Times. Evid Based Complement Alternat Med.; 2013: 964149. 
19. Lavanya N, Jayanthi P, Rao UK, Ranganathan K (2011): Oral Lichen Planus: An Update on Pathogenesis and Treatment. J Oral Maxillofac Pathol; 15: 127-32.

20. Metwaly H, AbdelMoneim M, Saku T (2014): Vascular Endothelial Growth Factor (VEGF) and Inducible Nitric Oxide Synthase ( Inos) in Oral Lichen Planus: An Immunohistochemical Study for the Correlation Between Vascular and Inflammatory Reactions. J Oral Maxillofac Surg Med \& Pathol. ;26:390-6.

21. Miyataka H, Nishiki M, Matsumoto H, Fijimoto T, Matsuka M, Satoh T (1997): Evaluation of Propolis. I. Evaluation of Brazilian and Chinese Propolis by Enzymatic and Physico-Chemical Methods. Biol. Pharm. Bull., 20, 496-501.

22. Moura S, Ferreira M, Andrade S, Reis M, Noviello M, Cara D (2011): Brazilian Green Propolis Inhibits Inflammatory Angiogenesis in A murine Sponge model. Evidence-Based Complementary and Alternative Medicine, 7 pages.

23. Norris D (1990): Cytokine Modulation of Adhesion Molecules in the Regulation of Immunologic Cytotoxicity of Epidermal Targets. J Invest Dermatol.; 95:111S-S20.

24. Overall CM, Wrana JL, Sodek J (1991): Transcriptional and Post-Transcriptional Regulation of 72-Kda Gelatinase/Type IV Collagenase by Transforming Growth Factor-Beta 1 in Human Fibroblasts. Comparisons with Collagenase and Tissue Inhibitor of Matrix Metalloproteinase Gene Expression. J Biol Chem; 266:14064-14071

25. Rhodus N, Cheng B, Ondrey F (2007): Th1/Th2 Cytokine Ratio in Tissue Transudates from Patients with Oral Lichen Planus. Mediators Inflamm. ;19854:1-5.

26. Sklavounou-Andrikopoulou A, Chrysomali E, Iakovou M, Garinis G, Karameris A |(2004): Elevated Serum Levels of the Apoptosis Related Molecules Tnfalpha. Fas/Apo-1 and Bcl-2 in Oral Lichen Planus. Oral Pathol Med. ;33:386-90.

27. Sugerman P, Savage N, Walsh L, Zhao Z, Zhou X, Khan A, Seymour G, Bigby M (2002): The Pathogenesis of Oral Lichen Planus. Crit Rev Oral Biol Med; 13: 350-65.

28. Thongprasom K, Luangjarmekorn L, Sererat T, Taweesap W (1992): Relative Efficacy of Fluocinolone Acetonide Compared with Triamcinolone Acetonide in Treatment of Oral Lichen Planus. J Oral Pathol Med. ;21:456-8.

29. van der Meij E, van der Waal I (2003): Lack of Clinicopathologic Correlation in the Diagnosis of Oral Lichen Planus Based on the Presently Available Diagnostic Criteria and Suggestions For Modifications. J Oral Pathol Med.; 32: 507-12.

30. Wael N, Gamal Badr, Ahmad A, Ayat Sayed, Noori S, Olivier (2015): Topical Application of Propolis Enhances Cutaneous Wound Healing by Promoting TGF-Beta/Smad-Mediated Collagen Production in a Streptozotocin-Induced Type I Diabetic Mouse Model. Cell Physiol Biochem; 37: 940-954.

31. Wagh VD (2013): Propolis: A Wonder Bees Product and Its Pharmacological Potentials. Adv Pharmacol Sci.; 11 pages.

32. Yu C, Weiping Z, Ning G, Kun T, Lester J (2008): Mmps, TIMP-2, And TGF-ß1 in the Cancerization of Oral Lichen Planus, Head and neck, 1247-1245.

33. Zauhani K, Pudji R, Muhaimin R, Edi W (2017):. Immunomodulatory Effect of Propolis Extract on Population of IL-10 and TGF- $\beta$ Expression in CD4+CD25+ Regulatory T Cells in DMBA-Induced Breast Cancer in Female Sprague-Dawley Rats. Turk J Immunol; 5(3)69-76. 